\section{Defining Low Disease Activity States in Psoriatic Arthritis Using Novel Composite Disease Instruments}

\section{To the Editor:}

We read with great interest the recent article by Coates and Helliwell on another definition of low disease activity using the novel composite indices to define remission in patients with psoriatic arthritis (PsA) ${ }^{1}$.

In 2010, the same authors developed a composite outcome measure as a target of treatment for patients with $\mathrm{PsA}^{2}$. Minimal disease activity (MDA) criteria are fulfilled when $5 / 7$ of the following criteria were satisfied: tender joint count $\leq 1$; swollen joint count $\leq 1$; Psoriasis Area and Severity Index $\leq 1$ or body surface area $\leq 3$; patient pain visual analog scale (VAS) score $\leq$ $15 \mathrm{~mm}$; patient global disease activity VAS score of $\leq 20 \mathrm{~mm}$; Health Assessment Questionnaire score $\leq 0.5$; and tender entheseal points $\leq 1$.

MDA criteria encompass most of the disease manifestations (including joint, skin, and enthesis); however, it would be possible for a patient to fulfill MDA criteria even if residual disease activity were present in at least 2 important domains such as tender and swollen joints.

In the latest article ${ }^{1}$, Coates and Helliwell proposed 2 new indices to define low disease activity/remission: MDA 7/7 criteria were fulfilled when all of the 7 classic MDA domains are satisfied, and MDA-joints, that is, the same as classic MDA 5/7 criteria but with the items for tender and swollen joints as mandatory. In their work the authors explored the equivalent cutoff levels for the Composite Psoriatic Disease Activity Index (CPDAI) ${ }^{3}$ and the Psoriatic Arthritis Disease Activity Score (PASDAS) ${ }^{4}$ with a well-structured analysis, to provide a more stringent definition of remission using different outcome measures.

However, in this article no information was available on the rate of patients with PsA reaching the MDA 7/7 criteria, that is, a very low disease activity, or the MDA-joints criteria in clinical practice.

In our recent prospective study ${ }^{5}$ we found that about $60 \%$ of 75 patients with PsA treated with anti-tumor necrosis factor agents reached the classic MDA (5/7) criteria after 12 months of therapy. The work by Coates and Helliwell prompted us to review our data and we found, as expected, that a lower rate $(37.3 \%)$ of our 75 patients reached an MDA $7 / 7$ criteria after 12 months of therapy, with a similar rate $(56 \%)$ of patients reaching the MDA-joints (Figure 1). Further analyzing our data, we found a very similar rate of patients achieving MDA 7/7 criteria and the Disease Activity Index for Psoriatic Arthritis (DAPSA) remission criteria ${ }^{6}$. We also confirmed an overall moderate to very good concordance between the different MDA criteria and with DAPSA (Table 1). In this context, our data could support the concept of a "deep" low disease activity when MDA 7/7 are reached, describing a condition of clinical remission. However, further studies are needed to define the role of MDA 7/7 or MDA-joints, in particular in relation to radiographic damage progression and the complete control of inflammation in patients with PsA. Indeed, we do believe that MDA 7/7 criteria and possibly DAPSA remission criteria could be used to define a state of very low disease activity because of their easy feasibility in real clinical practice.

ENNIO LUBRANO, MD, PhD; FABIO MASSIMO PERROTTA, MD; Academic Rheumatology Unit, Dipartimento di Medicina e Scienze della Salute "Vincenzo Tiberio," Università degli Studi del Molise, Via Giovanni Paolo II, C/da Tappino, 86100 Campobasso, Italy. Address correspondence to Dr. Lubrano; E-mail: enniolubrano@hotmail.com

\section{REFERENCES}

1. Coates LC, Helliwell PS. Defining low disease activity states in psoriatic arthritis using novel composite disease instruments. J Rheumatol 2016;43:371-5.

2. Coates LC, Fransen J, Helliwell PS. Defining disease activity in psoriatic arthritis: a proposed objective target for treatment. Ann Rheum Dis 2010;69:48-53

3. Helliwell PS, FitzGerald O, Fransen J. Composite disease activity and responder indices for psoriatic arthritis: a report from the GRAPPA 2013 meeting on development of cutoffs for both disease activity states and response. J Rheumatol 2014;41:1212-7.

4. Helliwell PS, FitzGerald O, Fransen J, Gladman DD, Kreuger GG, Callis-Duffin $\mathrm{K}$, et al. The development of candidate composite

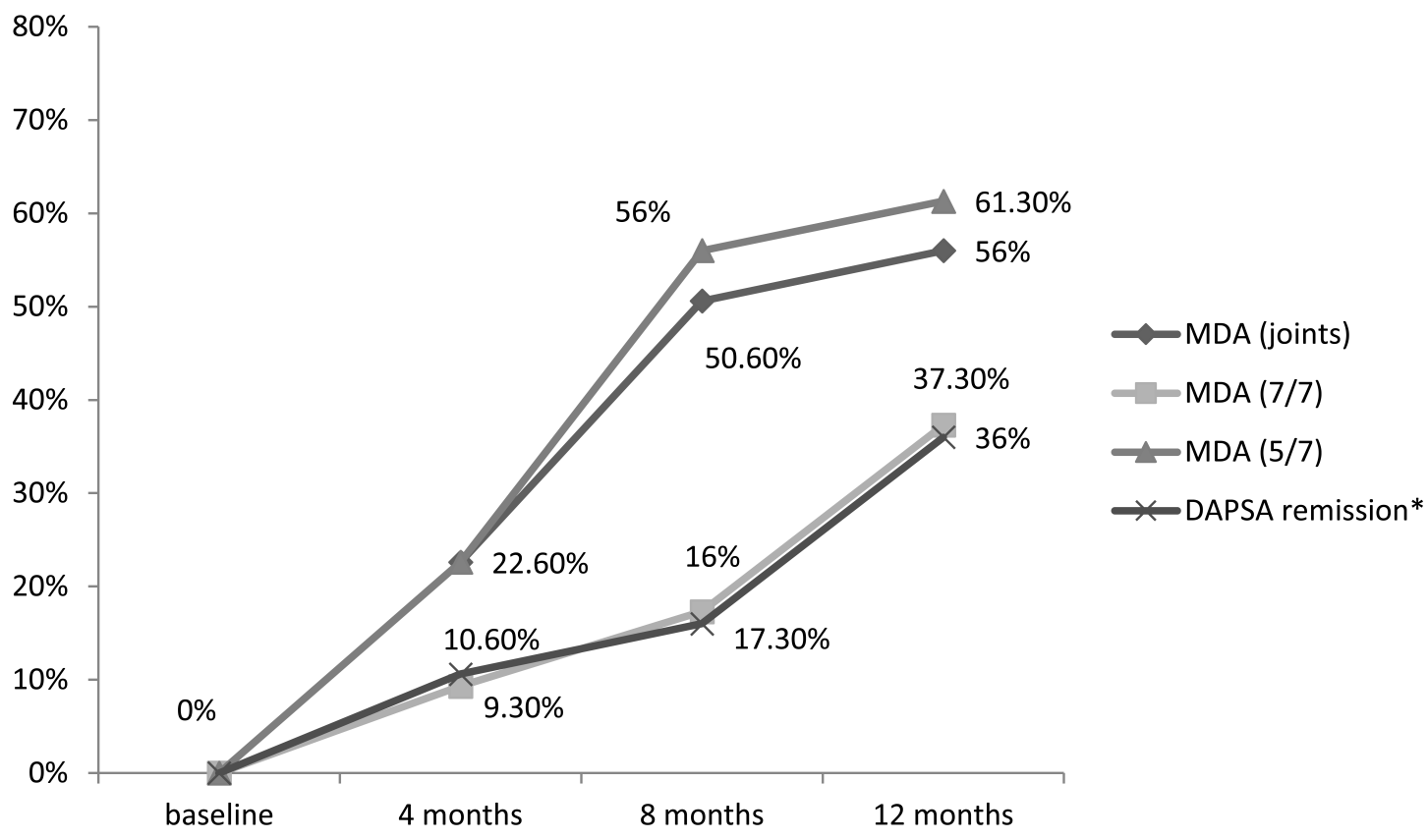

Figure 1. Percentage of patients who achieved classic MDA criteria, DAPSA remission, MDA-joints, and MDA (7/7) in our prospective study (Perrotta FM, et al. J Rheumatol 2016;43:350-5). *DAPSA remission is defined by DAPSA score $\leq 3.3$. MDA: minimal disease activity; DAPSA: Disease Activity Index for Psoriatic Arthritis.

Personal non-commercial use only. The Journal of Rheumatology Copyright @ 2016 . All rights reserved. 
Table 1. Concordance (Cohen's $\kappa)$ among the different criteria.

\begin{tabular}{cccccc}
\hline MDA vs MDA & $\begin{array}{c}\text { MDA vs DAPSA } \\
\text { Remission* }\end{array}$ & $\begin{array}{c}\text { MDA vs } \\
\text { MDA-joints }\end{array}$ & $\begin{array}{c}\text { MDA 7/7 vs } \\
\text { MDA-joints }\end{array}$ & $\begin{array}{c}\text { MDA 7/7 vs } \\
\text { DAPSA Remission* }\end{array}$ & $\begin{array}{c}\text { MDA-joints vs } \\
\text { DAPSA Remission* }\end{array}$ \\
\hline $12 \mathrm{mos}$ & 0.51 & 0.43 & 0.87 & 0.61 & 0.61 \\
\hline
\end{tabular}

*DAPSA remission is defined by DAPSA score $\leq 3.3$. MDA: minimal disease activity; DAPSA: Disease Activity Index for Psoriatic Arthritis.

disease activity and responder indices for psoriatic arthritis (GRACE project). Ann Rheum Dis 2013;72:986-91.

5. Perrotta FM, Marchesoni A, Lubrano E. Minimal disease activity and remission in psoriatic arthritis patients treated with anti-TNF- $\alpha$ drugs. J Rheumatol 2016;43:350-5.
6. Husic R, Gretler J, Felber A, Graninger WB, Duftner C, Hermann J, et al. Disparity between ultrasound and clinical findings in psoriatic arthritis. Ann Rheum Dis 2014;73:1529-36.

J Rheumatol 2016;43:9; doi:10.3899/jrheum.160386 